IOS Press

\title{
Thesis
}

\section{Vitruvius: Vehicle sensor based model-driven engineering application generation}

\author{
Vicente García-Díaz *, Jordán Pascual Espada and Guillermo Cueva Fernández \\ Department of Computer Science, University of Oviedo, Asturias, Spain \\ E-mails: garciavicente@uniovi.es, pascualjordan@uniovi.es,UO166447@uniovi.es
}

Keywords: Internet of things, vehicle, application Generation, sensor, fuzzy logic, decision making, adaptive system

On July 7, 2017 at 6 pm, Guillermo Cueva Fernández defended his Ph.D. thesis entitled Vitruvius: Vehicle Sensor Based Model-Driven Engineering Application Generation at the University of Oviedo. Guillermo Cueva Fernández presented his dissertation in a publicly open event held in the School of Computer Engineering, and was able to defend all his work on every question raised by his thesis committee and the audience. The thesis was supervised by his advisors, Jordán Pascual Espada and Vicente García-Díaz, together with the thesis committee, Juan Luis Pavón Mestras, Yago Sáez Achaerandio and José Emilio Labra Gayo. It has been approved, receiving the highest rating. All the cited people were present at the event.

\section{Thesis summary}

Internet of things promotes the use of physical intelligent connecting objects to automatize processes and tasks in multiple areas of society. There are numerous intelligent objects with different sensors and communication mechanisms. Today, road vehicles contain many advanced sensors that allow the collection of great amounts of parameters. With an appropriate communication mechanism, vehicles can be converted to intelligent objects capable of forming very useful systems in different areas such as road security, ve-

\footnotetext{
*Corresponding author. E-mail: garciavicente@ uniovi.es.
}

hicle maintenance, urban mobility, traffic congestion, fleet management, $\mathrm{CO} 2$ emissions, etc. The problem is that the implementation of a system is not quick or easy. Many subsystems and heterogeneous elements intervene. The lack of speed in the development can be a big inconvenient, especially when the environment is as dynamic as traffic, subject to many variables. Although there are several platforms that integrate intelligent objects and the generation of applications, none of them are focused on road vehicles. In our research, we worked on Vitruvius, a platform where users with no programming knowledge can design and quickly implement rich Web applications based on real time data consumption from interconnected vehicles and sensors.

Figure 1 shows a general overview of the main components of the Vitruvius platform, that was designed to simplify the collection of vehicle information in order to generate applications quickly [4]. First, a mechanism for obtaining data for vehicles was created [5]. This part of the work presents a Fuzzy method that can be used to improve the performance of mobile clients in real-time systems [3]. The proposal integrates the algorithm in different mobile clients of the Vitruvius platform. These applications have been developed, initially, for Android operating systems, allowing to send all the information coming from vehicle sensors and mobile devices to a platform service. Once the information is transmitted to the Vitruvius repository (whose main functions are the management and 


\section{Web Interface}

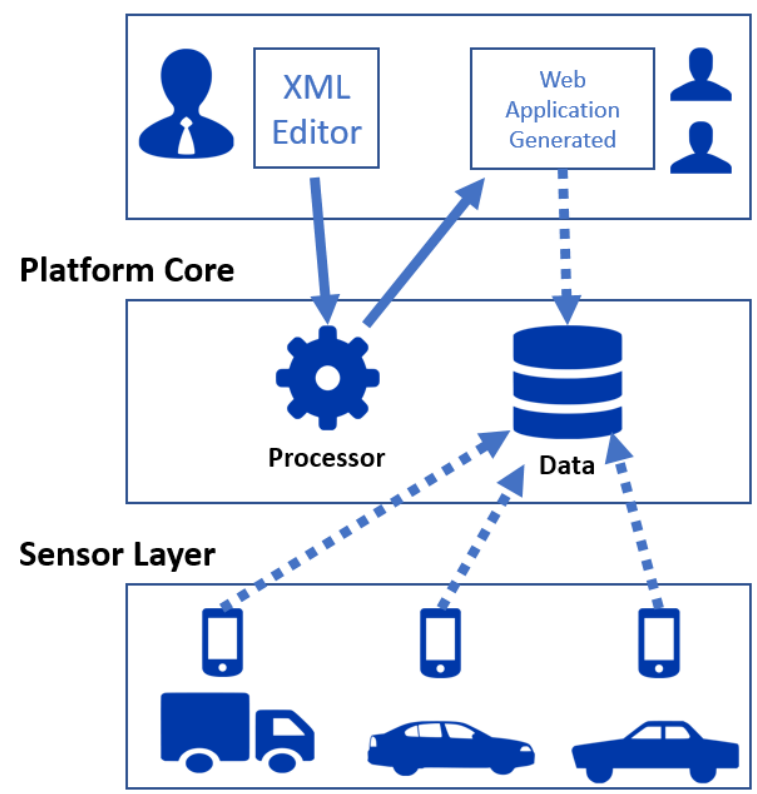

\section{Vitruvius Approach}

Fig. 1. Vitruvius overview.

storage of data from vehicles), it becomes available to be consumed by Web applications generated by users.

The information obtained from the sensors is used in the applications that are created by Vitruvius to alert and display in real time information about connected cars. All applications generated from the platform are oriented to vehicles but open to be adapted to other fields. The focus of the work is based on cases where the information can be combined, and merged to determine events of interest for different users.

A language was developed as a mechanism for the definition of applications on the platform. The main motivation was the creation of a simple language to get a quick familiarization with novel users. Two generators were created to help with the development of applications. The first application generator is based on a Web editor with a wizard. New users with no experience have been able to create applications even in a time close to skilled users of the platform. The second application generator is based on a smart voice recognition system [1]. The solution integrates three different user profiles for voice interaction. Depending on the case, these profiles include more or less detail in the instructions and include different options. The proposed system captures real-time information about user interaction and the information that it uses to de- termine whether the user is comfortable with the wizard. The system uses a series of Fuzzy rules to determine whether it is necessary to change the profile to obtain the best user experience and thus reducing the number of failed interactions and the total time in completing actions [2].

The results suggest that the proposal simplifies and improves the speed in the generation of applications compared to traditional development. Obviously, the platform does not cover all the possible applications that could be generated with traditional software development. However, the platform could cover the needs of users in certain scenarios without technical knowledge. For this reason, the platform could be used by the general public or by expert users to monitor numerous aspects related to vehicles.

Further, with the future increase in the number of autonomous vehicles, both terrestrial and aerial, the use of the Vitruvius platform could improve the efficiency of communications and optimize network resources, as well as allow the creation of applications to users for different types of needs. The flexibility of the platform allows it to be used with many types of sensors, which would be suitable for vehicles with special needs.

Finally, the following lines of future work have been established:

- Provide an alternative visual language using a new interface to generate applications that reduce complexity to new users.

- Include analytics tools to analyze the large amount of data coming from vehicles in order to anticipate future possible events.

- Develop methods for horizontal communication between vehicles with the objective of sharing data that can help improve driving and the environment.

\section{References}

[1] G. Cueva-Fernandez, J. Pascual Espada and V. García-Díaz, Voice application generator platform for real time multimedia vehicle sensor based notifications, International Journal of Handheld Computing Research 6(1) (2015), 20-33. doi:10. 4018/IJHCR.2015010102.

[2] G. Cueva-Fernandez, J. Pascual Espada, V. García-Díaz, R.G. Crespo and N. Garcia-Fernandez, Fuzzy system to adapt web voice interfaces dynamically in a vehicle sensor tracking application definition, Soft Computing 20(8) (2016), 33213334. doi:10.1007/s00500-015-1709-2. 
[3] G. Cueva-Fernandez, J. Pascual Espada, V. García-Díaz and R. Gonzalez-Crespo, Fuzzy decision method to improve the information exchange in a vehicle sensor tracking system, Applied Soft Computing 35 (2015), 708-716. doi:10.1016/j.asoc.2015. 01.066 .

[4] G. Cueva-Fernandez, J. Pascual Espada, V. García-Díaz, C. Gonzalez-Garcia and N. Fernandez-Garcia, Vitruvius: An expert system for vehicle sensor tracking and managing applica- tion generation, Journal of Network and Computer Applications 42 (2014), 178-188. doi:10.1016/j.jnca.2014.02.013.

[5] G. Cueva-Fernandez, J. Pascual Espada, V. García-Díaz and M. Gonzalez-Rodriguez, Kuruma: The vehicle automatic data capture for urban computing collaborative systems, International Journal of Interactive Multimedia \& Artificial Intelligence 2(2) (2013), 28-32. doi:10.9781/ijimai.2013.223. 